\title{
Purification, Characterization, and Biocatalytic and Antibiofilm Activity of a Novel Dextranase from Talaromyces sp.
}

\author{
Mahasen Mohamed Ahmed Ebaya (iD, Mohammed El-Mowafy (D), \\ Mohamed Mohamed Adel El-Sokkary ${ }^{(D)}$, and Ramadan Hassan \\ Department of Microbiology and Immunology, Faculty of Pharmacy, Mansoura University, Mansoura 35516, Egypt \\ Correspondence should be addressed to Mohamed Mohamed Adel El-Sokkary; m_elsokkary2022@yahoo.com
}

Received 17 March 2020; Revised 6 September 2020; Accepted 2 November 2020; Published 11 November 2020

Academic Editor: Karl Drlica

Copyright ( 2020 Mahasen Mohamed Ahmed Ebaya et al. This is an open access article distributed under the Creative Commons Attribution License, which permits unrestricted use, distribution, and reproduction in any medium, provided the original work is properly cited.

\begin{abstract}
Dextranase is a useful enzyme that catalyzes the degradation of dextran to low-molecular-weight fractions, which have many critical commercial and clinical applications. Endophytic fungi represent a source of both high heat-stable and pH-stable enzymes. In this study, from Delonix regia bark by plate assay, out of 12 isolated fungal strains, hyaline zones were detected in only one strain. By using the standard ITS rDNA sequencing analysis, the isolated strain was identified as Talaromyces sp. In the case of carbon source, in a medium containing 1\% dextran T2000 as the sole carbon source, the maximum dextranase activity reached approximately $120 \mathrm{U} / \mathrm{ml}$ after incubation of 2 days where the optimum $\mathrm{pH}$ was 7.4. Peptone addition to the production medium as a sole nitrogen source was accompanied by a significant increase in the dextranase production. Similarly, some metal ions, such as $\mathrm{Fe}^{2+}$ and $\mathrm{Zn}^{2+}$, increased significantly enzyme production. However, there was no significant difference resulting from the addition of $\mathrm{Cu}^{2+}$. The crude dextranase was purified by ammonium sulfate fractionation, followed by Sephadex G100 chromatography with 28-fold purification. The produced dextranase was $45 \mathrm{kDa}$ with an optimum activity at $37^{\circ} \mathrm{C}$ and a pH of 7 . Moreover, the presence of $\mathrm{MgSO}_{4}, \mathrm{FeSO}_{4}$, and $\mathrm{NH}_{4} \mathrm{SO}_{4}$ increased the purified dextranase activity; however, SDS and EDTA decreased it. Interestingly, the produced dextranase expressed remarkable $\mathrm{pH}$ stability, temperature stability, and biofilm inhibition activity, reducing old-established biofilm by $86 \%$ and biofilm formation by $6 \%$.
\end{abstract}

\section{Introduction}

Dextranase, $\alpha$-1,6-d-glucan-6- glucanohydrolase, is an inducible enzyme that cleaves the $\alpha$-1,6-glycosidic linkages in dextrans resulting in the hydrolysis of high molecular weight dextrans to low-molecular-weight fractions [1-3]. Dextranases produced by various fungi, bacteria, and other microorganisms are extensively used for research purposes [4]. In medicine, the partial dextranase hydrolysis of native dextran generates specific molecular weight fractions used in preparing blood substitutes to restore blood volume in shocked patients due to extreme blood loss [5-8]. On the other hand, dextranase plays an efficient role in food industries, such as molasses and beverage processing [9]. In the sugar industry, dextranase could minimize the dextran residues in sugarcane juice, which interferes with the sugar manufacturing process [10], avoiding the tremendous loss in sucrose quantity and improving the quality of produced sugar [11-13].

In oral hygiene, dextranase can be used in oral care products such as dental paste and mouthwashes to remove dental plaque and prevent dental caries. Different dextranase-producing microorganisms, such as bacteria, mold, and yeast, have been previously reported in various studies $[4,14-17]$. As previously documented, fungi are the most common commercial sources of dextranase with high enzymatic activity and low immunological effects, compared to those produced by bacteria and other microorganisms $[2,18]$. Endophytic fungal enzymes have great pharmaceutical, industrial, and agricultural importance and demonstrate various biological activities resulting from their endophytic natural products $[19,20]$. 
Previous studies have shown that most isolated dextranases have been characterized by low heat and $\mathrm{pH}$ stability [1, 21]. Generally, fungal endophytes improve the performance of plants and resistance against different stresses and afford them unique adaptation via the production of bioactive compounds [22, 23]. Consequently, endophytic fungi may produce fungal enzymes highly beneficial in the enzyme industry due to their reasonable stability at high-temperature levels and extreme $\mathrm{pH}$ values. The main objectives of this study were to isolate endophytic fungi producing dextranase and to optimize the production condition of this enzyme.

\section{Materials and Methods}

2.1. Isolation of Endophytic Fungal Strains and Primary Screening for Dextranase-Producing Strains. Several fungal strains were isolated from the Delonix regia plant, which grows in Egypt's Delta region. A total of 12 endophytic fungal strains were collected. The resulting fungal strains were streaked for purification on yeast peptone dextrose agar (YPD) plates and incubated at $28^{\circ} \mathrm{C}$ for $3-8$ days. Afterwards, a separate colony of each isolate was subcultured on dextranase production-screening medium ( $\mathrm{pH}$ 5.5) containing $1 \%$ dextran T2000 [(2000 kDa) Pharmacia products (Uppsala, Sweden)], $0.3 \% \quad \mathrm{NaNO}_{3}, \quad 0.05 \% \mathrm{KCl}, \quad 0.1 \%$ $\mathrm{K}_{2} \mathrm{HPO}_{4} \cdot 3 \mathrm{H}_{2} \mathrm{O}, 0.05 \% \mathrm{MgSO}_{4} \cdot 7 \mathrm{H}_{2} \mathrm{O}, 0.001 \% \mathrm{FeSO}_{4} \cdot 7 \mathrm{H}_{2} \mathrm{O}$, and $1.5 \%$ agar powder, a nd the results were detected after 5 days of incubation at $28^{\circ} \mathrm{C}$ [1]. Positive dextranase-producing strains produced a hyaline (clear) zone against the turbid background of this medium.

2.2. Identification of Dextranase-Producing Endophyte. For identification of the dextranase-producing fungal strain, the ribosomal internal transcribed spacer (ITS) was amplified using the universal ITS1 (TCCGTAGGTGAACCTGCGG) and ITS4 (TCCTCCGCTTATTGATATGC) primers (Biosearch Technologies, UK). The target PCR product (581 bp) was used as a template in sequencing reactions using the ABI PRISM ${ }^{\circledR}$ BigDye Terminator Cycle Sequencing Ready Reaction Kit (Applied Bio-Systems, Foster City, USA). The reaction mixtures were analyzed on an ABI 3730 DNA analyzer (Applied Biosystems, Foster City, USA). Based on the DNA gene sequences of dextranase-producing strain and related organisms from the GenBank, multiple DNA sequence alignment was performed using the software package MEGA4 version. For the detection of isolated fungal strain, a phylogenetic tree was constructed using the bootstrap test of neighborjoining algorithm after 1000 times.

\subsection{Culture Conditions for Crude Dextranase Production and} Optimization of Incubation Time. For the production of extracellular dextranase, the production liquid culture medium was composed of (g\%) 1.5\% dextran T2000, 0.1\% $\mathrm{K}_{2} \mathrm{HPO}_{4} .3 \mathrm{H}_{2} \mathrm{O}, 0.4 \%$ yeast extract, $0.05 \% \mathrm{MgSO}_{4} .7 \mathrm{H}_{2} \mathrm{O}$, and $\mathrm{pH} 7.4$ [24]. The spore count was adjusted to $10^{7}$ spores $/ \mathrm{ml}$ using a direct microscopic counting hemocytometer [10]. For submerged culture fermentation, one milliliter of the adjusted spore suspension of the dextranase-producing strain was suspended in this medium $(50 \mathrm{ml})$ followed by incubation in a rotary shaker $(200 \mathrm{rpm})$ at $30^{\circ} \mathrm{C}$ for 7 days. Afterward, the content of each flask was filtered, followed by centrifugation at $6000 \mathrm{rpm}$ for $20 \mathrm{~min}$ at $4^{\circ} \mathrm{C}$. The supernatant was then tested for enzyme activity $[1,25]$ and stored at $-80^{\circ} \mathrm{C}$ until further analyses of dextranase production.

2.4. Assay of Dextranase Production. Dextranase activity was determined by measuring the reducing sugar liberated during enzyme-substrate interaction via the microplate colorimetric assay developed by Somogyi and Nelson with slight modifications [26-28]. In a 96-well microplate, $25 \mu \mathrm{l}$ of enzyme sample was incubated with $25 \mu \mathrm{l}$ of $1 \%$ dextran T2000 solubilized in $0.1 \mathrm{M}$ citrate buffer ( $\mathrm{pH} 5$ ) in each well at $37^{\circ} \mathrm{C}$. After $24 \mathrm{~h}$ of incubation, $50 \mu \mathrm{l}$ of freshly prepared Somogyi copper reagent was added; then the wells were sealed with the acetate sheet followed by incubation in a water bath at $80^{\circ} \mathrm{C}$ for $30 \mathrm{~min}$. Plate cooling was performed with running cooled water for $5 \mathrm{~min}$ followed by the addition of $50 \mu \mathrm{l}$ of arsenomolybdate reagent $(2.5 \mathrm{~g}$ ammonium molybdate, 3 g sodium arsenate, $2.1 \mathrm{ml}$ concentrated sulfuric acid, and $45 \mathrm{ml}$ water) in each well. Colorimetric measurements were performed at $500 \mathrm{~nm}$ using microplate spectrophotometer reader ELx808 ${ }^{\mathrm{TM}}$ (Biotek Instruments Inc., Winooski, VT). The standard curve was constructed using maltose at concentrations ranging from 100 to $2000 \mu \mathrm{g} / \mathrm{ml}$. One unit (U) of dextranase enzyme activity was defined as the amount of enzyme required to catalyze the formation of $1 \mathrm{~mol}$ of maltose in $1 \mathrm{~min}$ at standard assay condition $(\mathrm{U} / \mathrm{ml})$. Other values were calculated as follows:

The specific activity $(\mathrm{U} / \mathrm{mg})=$ total activity $(\mathrm{U}) /$ total protein amount $(\mathrm{mg})$, where total activity $(\mathrm{U})=$ enzyme activity $(\mathrm{U} / \mathrm{ml}) \times$ volume of enzyme solution, while total protein $=$ protein concentration $(\mathrm{mg} / \mathrm{ml}) \times$ volume of protein solution [29].

2.5. Determination of Protein Concentration. The protein concentration $(\mathrm{mg} / \mathrm{ml})$ was determined using the Bradford method using Bradford reagent (Thermo Fisher Scientific, USA) [30]. The standard curve of bovine serum albumin (BSA) was constructed by plotting different concentrations of bovine serum albumin (BSA) (Sigma-Aldrich, USA), which was used as standard protein against their absorbance values at $595 \mathrm{~nm}$ as read by the microplate spectrophotometer reader. Each protein concentration was calculated in $\mathrm{mg} / \mathrm{ml}$ based on absorbance measurements at $595 \mathrm{~nm}$ compared to standard.

2.6. Optimization of Different Factors Affecting Dextranase Activities. Different factors affecting dextranase activities were investigated in the inoculated dextranase production media as previously described conditions for submerged culture fermentation. 
2.6.1. Optimization of Carbon Source for Dextranase Production. For maximum dextranase production, various carbon sources, such as glucose, starch, and sucrose, were added at a concentration of $1.5 \%$ in growth medium instead of dextran T2000.

2.6.2. Optimization of Nitrogen Source and Concentration for Dextranase Production. For maximum dextranase production, various organic and inorganic nitrogen sources substituting yeast extract such as peptone, tryptone, urea, potassium nitrate, sodium nitrate, and ammonium sulfate were supplemented at a concentration of $0.4 \%$.

2.6.3. Optimization of Medium $p H$ for Dextranase Production. The effect medium $\mathrm{pH}$ was tested within a wide range from 3 to 8.5 using $1 \mathrm{~N} \mathrm{HCl}$ and $1 \mathrm{~N} \mathrm{NaOH}$ before sterilization. By the standard assay procedure, the enzymatic activity of each $\mathrm{pH}$ medium was calculated to determine optimum $\mathrm{pH}$ for enzyme production.

2.6.4. Effects of Metal Ions and Other Reagents on Dextranase Production. The effect of some metal ions was estimated separately at a concentration of $0.05 \%$ under standard assay conditions using $\mathrm{Cu}^{2+}\left(\mathrm{CuSO}_{4}\right), \mathrm{Zn}^{2+}\left(\mathrm{ZnSO}_{4}\right)$, and $\mathrm{Fe}^{2+}$ $\left(\mathrm{FeSO}_{4}\right)$ in $\mathrm{Mg}^{2+}$ ion $\left(\mathrm{MgSO}_{4}\right)$ free production medium.

2.7. Dextranase Enzyme Purification. Crude enzyme extract was treated with saturated ammonium sulfate solutions ranging from 20 to $90 \%$, followed by incubation at $4^{\circ} \mathrm{C}$ with magnetic stirring. After overnight incubation, the precipitated proteins were collected by centrifugation at $10,000 \mathrm{rpm}$ for $20 \mathrm{~min}$ at $4^{\circ} \mathrm{C}$, followed by dissolution in $0.01 \mathrm{M}$ potassium phosphate buffer $(\mathrm{pH} 7)$. The resulting extracted proteins were dialyzed in the same buffer overnight at $4^{\circ} \mathrm{C}$. Further purification of the concentrated dialyzed enzyme was performed on a Sephadex G100 column preequilibrated with potassium phosphate buffer $(\mathrm{pH} 7)$ at low temperature with a flow rate of $0.2 \mathrm{ml} / \mathrm{min}$. One hundred fractions $(2 \mathrm{ml}$ each) were collected after column separation, followed by absorbance measurements at $280 \mathrm{~nm}$ to monitor the concentration of separated proteins [31].

After determining the enzyme activity, fractions with high dextranase activity were pooled together, followed by determining their molecular weight by $12 \%$ sodium dodecyl sulfate-polyacrylamide gel electrophoresis separation (SDSPAGE) followed by Coomassie Brilliant Blue staining [32].

2.8. Effect of Different Parameters on Activity and/or Stability of Dextranase Enzyme. The incubation temperature effect on dextranase activity was measured at 25, 30, 37, 40, 50, and $60^{\circ} \mathrm{C}$. Relative activity was expressed as a percentage of the highest activity, while the highest dextranase activity was $100 \%$. The thermostability of dextranase was tested without substrate addition by treating for $1 \mathrm{~h}$ at $20-90^{\circ} \mathrm{C}$ in $0.01 \mathrm{M}$ potassium phosphate buffer $(\mathrm{pH} 7)$. The control sample at $100 \%$ activity was used as the maximum enzyme activity.
For studying the effect of $\mathrm{pH}$, the purified dextranase enzyme activity was determined at a $\mathrm{pH}$ range of 3.0-10.0 (citrate-sodium citrate buffer, $\mathrm{pH}$ 3.0-6.0; potassium phosphate buffer, pH 7.0-8.0; carbonate-bicarbonate buffer, $\mathrm{pH}$ 9-10). Relative activity was expressed as a percentage of the highest activity, while the highest dextranase activity was calculated as $100 \%$. The $\mathrm{pH}$ stability of dextranase activity was tested at $3.0-10 \mathrm{pH}$ range for $1 \mathrm{~h}$ at $37^{\circ} \mathrm{C}$ using the same buffers. Relative activities were expressed as percentages of the maximum activity. Furthermore, the effects of several metal ions and reagents, namely, $\mathrm{MgSO}_{4}, \mathrm{NH}_{4} \mathrm{SO}_{4}, \mathrm{FeSO}_{4}$, $\mathrm{NaCl}, \mathrm{SDS}$, and EDTA, influencing dextranase activity were investigated at 3 different concentrations, $1 \mathrm{mM}, 5 \mathrm{mM}$, and $10 \mathrm{mM}$.

2.9. Quantitative Detection of Biofilm Activities. For quantitative determination of biofilm production, standard strain $P$. aeruginosa PAO1 (Microbiology and Immunology Department culture collection) TSBG (tryptic soy broth supplemented with $1 \%$ glucose) overnight culture was adjusted to $0.2-0.25$ at $600 \mathrm{~nm}\left(\mathrm{OD}_{600 \mathrm{~nm}}\right)$ using a spectrophotometer (WPA colorwave CO7500 Colorimeter) [33]. Afterward, $100 \mu \mathrm{l}$ aliquots of preadjusted culture were inoculated in four adjacent vertical wells, in addition to the negative control (TSBG only), followed by incubation at $37^{\circ} \mathrm{C}$ for $24 \mathrm{~h}$. After overnight incubation, the content of each well was removed and washed three times with $200 \mu \mathrm{l}$ phosphate buffered saline (PBS) [0.01 M, pH 7.4]. Adherent cells of each well were fixed by treatment with $150 \mu \mathrm{l}$ absolute methanol for $15 \mathrm{~min}$, followed by aspiration of methanol. After drying, each well was stained by $150 \mu \mathrm{l}$ of $1 \%(\mathrm{w} / \mathrm{v})$ crystal violet and left for $20 \mathrm{~min}$; then the plate was rinsed three times with distilled water and air-dried. The resulting bound biofilm was resolubilized by adding $150 \mu \mathrm{l} 33 \%$ (v/v) glacial acetic acid per well. At $540 \mathrm{~nm}$, measurements were performed using ELx808 ${ }^{\mathrm{TM}}$ Absorbance Microplate Reader (BioTek Instruments Inc., Winooski, VT) [34-37].

2.9.1. The Effect of the Enzyme on Biofilm Production. For determination of the antibiofilm enzyme activity, $100 \mu \mathrm{l}$ of the purified enzyme $(5 \mathrm{U})$ in $0.01 \mathrm{M}$ potassium phosphate buffer was added in 4 replicates to $100 \mu \mathrm{l}$ of OD-adjusted bacterial suspension, followed by incubation at $37^{\circ} \mathrm{C}$ for $24 \mathrm{~h}$ without shaking. As a negative control, $100 \mu \mathrm{l} 0.01 \mathrm{M}$ potassium phosphate buffer was used to substitute the purified enzyme. After incubation, biofilm activity was determined as described above.

\subsubsection{The Effect of the Enzyme on Old Established Biofilm.} For the investigation of the dextranase impact on the $24 \mathrm{~h}$ old-established biofilm of PAO1 strain, $100 \mu \mathrm{l}$ of the purified enzyme $(5 \mathrm{U})$ in $0.01 \mathrm{M}$ potassium phosphate buffer $(\mathrm{pH} 7)$ was added into 4 wells harboring $24 \mathrm{~h}$ old-established biofilms of the standard strain PAO1, followed by incubation $24 \mathrm{~h}$ at $37^{\circ} \mathrm{C}$. Negative controls were prepared by adding $100 \mu \mathrm{l}$ potassium phosphate buffer $(0.01 \mathrm{M}, \mathrm{pH} 7)$ into 4 wells harboring $24 \mathrm{~h}$ old biofilms of the same strain PAO1. 


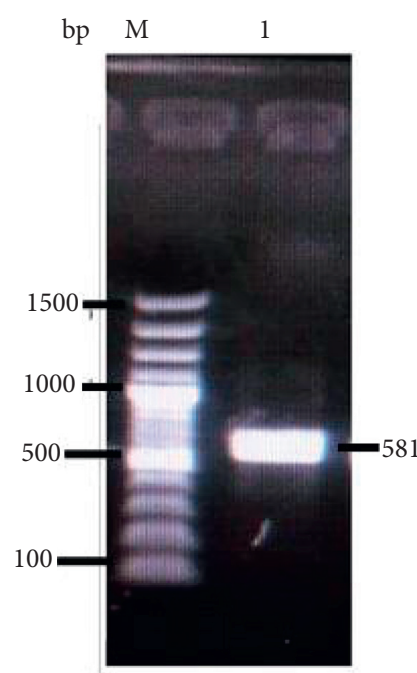

(a)

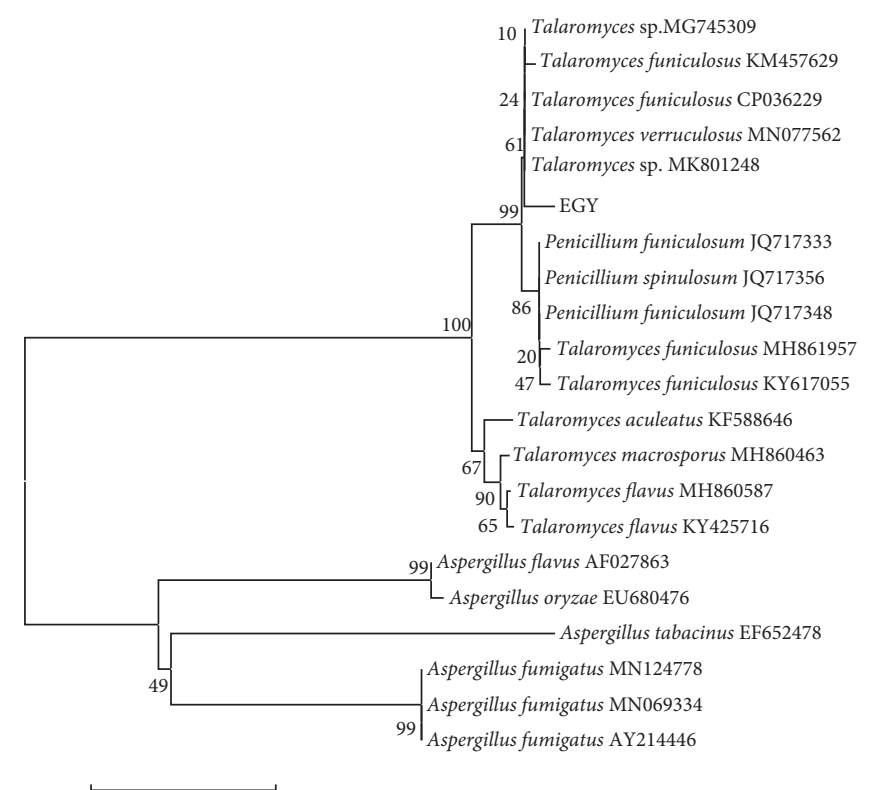

(b)

FIgURE 1: Molecular identification of dextranase-producing strain (Talaromyces sp.) based on ITS region sequence analysis. (a) PCR amplification of DNA of the fungal strain (EGY) using universal primers (ITS1/ITS4). Lane 1: PCR products were resolved by $1 \%$ agarose gel electrophoresis. M: 100 bp DNA ladder (Thermo Scientific GeneRuler 100 bp Plus). (b) Phylogenetic tree based on ITS rRNA gene sequences.

Biofilm reducing activities were quantified after overnight incubation. Relative biofilm reducing activities were calculated as percentages relative to the negative controls (set as 0 $\%$ reduction percent).

2.10. Statistical Analysis. Data were analyzed using OneWay ANOVA followed by Bonferroni's test using SPSS software.

\section{Results and Discussion}

3.1. Screening and Identification of Dextranase-Producing Strains. Under the aerobic conditions, only one isolate (named EGY) formed a hyaline zone on the screening media plate by degrading dextran T2000. The phylogenetic tree was constructed, including the ITS rDNA sequence (581 bp) of the isolated strain and some sequences obtained from the gene bank (Figure 1). As a result, the isolated strain was identified as Talaromyces sp.

\subsection{Effect of Incubation Time on Dextranase Production.} Generally, the incubation period differs according to the microbial growth rate and the pattern of the enzyme production [10]. After $48 \mathrm{~h}$ of incubation, the dextranase activity increased to its maximum production reaching approximately $120 \mathrm{U} / \mathrm{ml}$ (Figure 2). Similarly, in 2014, Cai et al. found that the optimal incubation time for dextranase production from Catenovulum sp. was within the range of 0 and $48 \mathrm{~h}$ [38]. In contrast, maximum yields of dextranase were attained after 5 days of Paecilomyces lilacinus and 7 days of incubation of Fusarium sp. and Penicillium aculeatum $[10,39]$.

3.3. Optimization of Carbon Source for Dextranase Production. Different carbon sources such as dextran, glucose, starch, and sucrose were added as a sole carbon source in the dextranase production medium. The maximum dextranase production was achieved when only dextran T2000 was incorporated in the culture medium, while no enzyme production was detected in media supplemented with glucose, sucrose, or starch (Figure 3). These results suggested that dextranase enzyme production is highly substrate-specific and inducible. Some studies previously reported that increases in microbial growth and dextranase production could be observed when using dextran as a carbon source [40-43].

3.4. Optimization of Nitrogen Source for Dextranase Production. Some organic and inorganic nitrogenous sources were tested for their role in the production of the dextranase enzyme. The yeast extract, peptone, and tryptone supported higher enzyme production in the $2^{\text {nd }}$ day of incubation but interacted differently; the peptone resulted in a significant increase in enzyme production compared to yeast extract. In contrast, no significant difference between tryptone and yeast extract could be traced (Figure 4). Similar results were detected in another study, starting from Bacillus sp. as a dextranase-producing microorganism [41]. Additionally, yeast extract and peptone were associated with high dextranase production levels from Catenovulum sp., while 


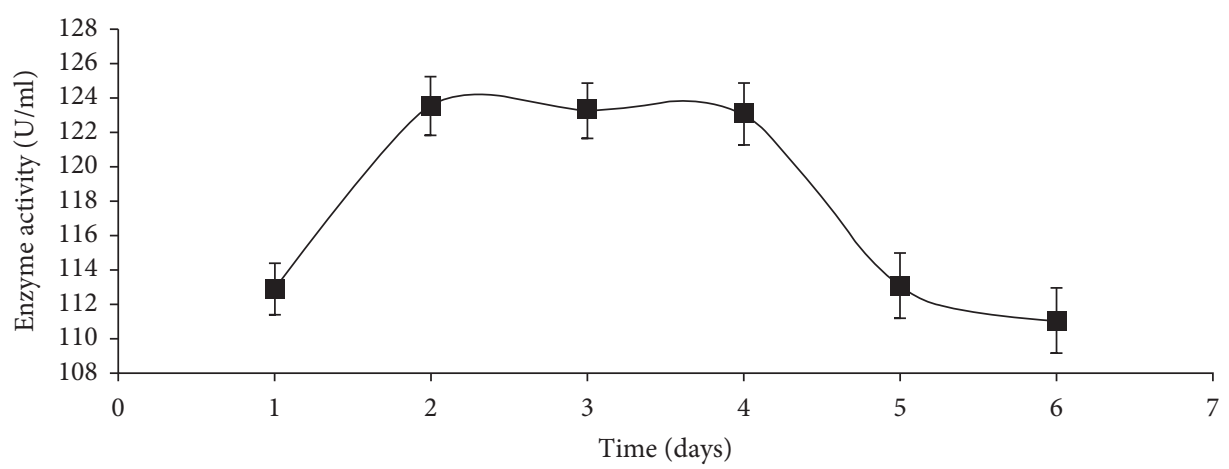

FIgURE 2: Effect of incubation time on dextranase production from Talaromyces sp.

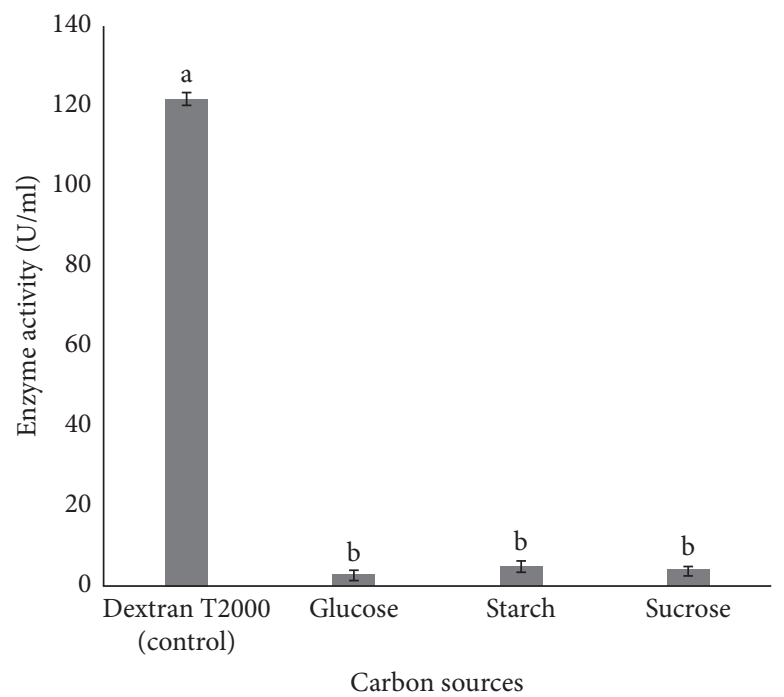

Figure 3: Effect of carbon sources on dextranase production from Talaromyces sp. at the second day of fermentation. Symbols (mean \pm SE, $n=6$ ) having similar letters are not significantly different from each other (Bonferroni, $P<0.0125$ ).

soybean powder, cornmeal, and casein decreased dextranase production. Moreover, the inorganic nitrogen sources, such as ammonium nitrate, urea, potassium nitrate, and ammonium phosphate, had no significant effects on dextranase production. The same observation was previously detected using inorganic nitrogen sources such as ammonium sulfate and ammonium nitrate [38].

3.5. Optimization of $p H$ for Dextranase Production. The effect of the initial $\mathrm{pH}$ of culture media on dextranase production was studied over a $\mathrm{pH}$ range of 3 to 8.5. The maximum yield of the enzyme was attained at $\mathrm{pH} 7.4$; however, a remarkable decline in enzyme production was observed when the $\mathrm{pH}$ of the media gradually decreased (Figure 5). Some studies have indicated that maximal dextranase enzyme yield from Penicillium funiculosum and Catenovulum sp. could be reached at an initial $\mathrm{pH}$ of $8.0[17,38]$. In contrast, the optimum dextranase production by different fungal species could be achieved at the $\mathrm{pH}$ range from 5.5 to 6.0 $[10,16,39,44]$.
3.6. Effect of Metal Ions on Dextranase Production. The effects of some metal ions on dextranase production compared to $\mathrm{Mg}^{+2}$ were estimated. The addition of either $\mathrm{Fe}^{+2}$ or $\mathrm{Zn}^{+2}$ resulted in a significant increase in enzyme production. However, there was no significant effect resulting from the addition of $\mathrm{Cu}^{+2}$ (Figure 6).

3.7. Identification of Purified Enzyme. Talaromyces sp. crude dextranase enzyme was primarily concentrated by $70 \%$ ammonium sulfate treatment. The specific activity of this partially purified enzyme was $385 \mathrm{U} / \mathrm{mg}$ (Table 1). The dextranase enzyme was further purified by gel filtration chromatography using Sephadex G100. Samples from tubes $19,20,21$, and 22 were merged and analyzed by SDS-PAGE. The purified dextranase in the merged fractions appeared as a single band (Figure $7(\mathrm{a})$ ), suggesting a monomer separated by an efficient purification process, purified to 28 -fold concentration with a $6 \%$ yield and $3429 \mathrm{U} / \mathrm{ml}$ specific activity (Table 1). The molecular weight of the purified dextranase was about $45 \mathrm{kDa}$ (Figure $7(\mathrm{~b})$ ), which is different 


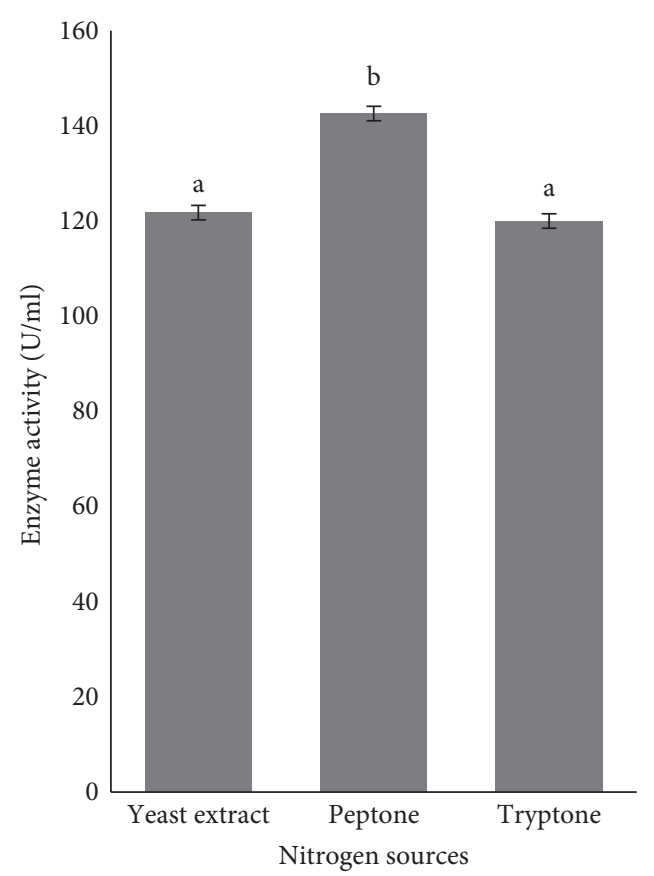

Figure 4: Effect of nitrogen sources on dextranase production from Talaromyces sp. at the second day of fermentation. Symbols (mean \pm SE, $n=6$ ) having similar letters are not significantly different from each other (Bonferroni test, $P<0.017$ ).

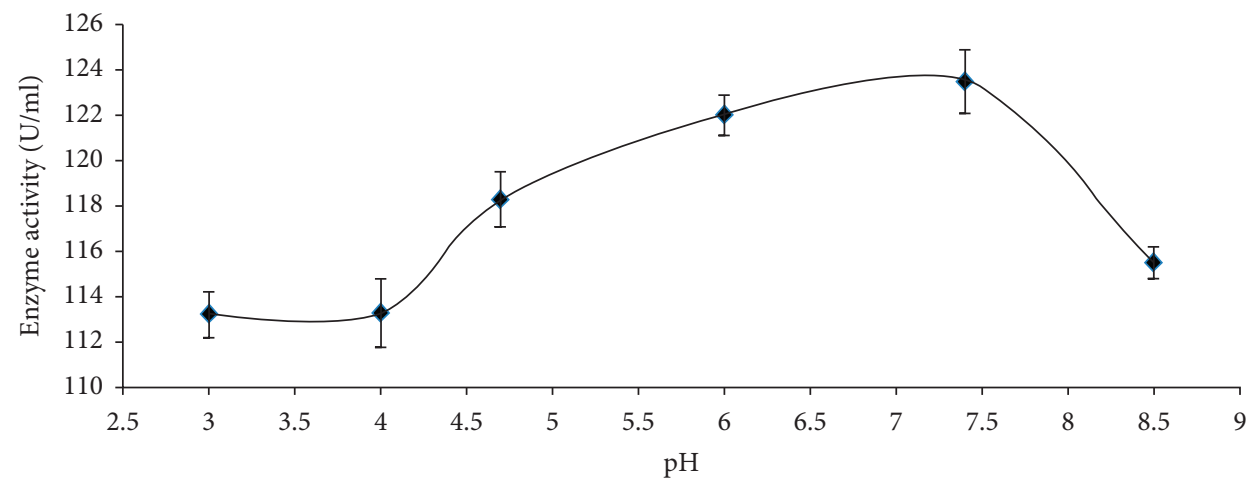

FIGURE 5: Effect of initial $\mathrm{pH}$ in the medium on the dextranase production from Talaromyces sp. at the second day of fermentation.

from other previously reported fungal dextranases such as Aspergillus allahabadii X26 (66 kDa) [12], Talaromyces pinophilus H6 (58 kDa) [45], Penicillium aculeatum (66.2 kDa) [21] Penicillium cyclopium (66 kDa) [46], and Chaetomium globosum (53 kDa) [31].

\subsection{Dextranase Enzymatic Properties}

3.8.1. Effects of Temperature and $p H$ on Dextranase Activity and Stability. The effect of $\mathrm{pH}$ and temperature was studied on Talaromyces sp. dextranase activity. An optimum temperature of $37^{\circ} \mathrm{C}$ was obtained. The thermal stability assessment of dextranase revealed that the enzyme retained greater than $80 \%$ residual activity after storage at $20-70^{\circ} \mathrm{C}$ for $1 \mathrm{~h}$. Furthermore, a $\mathrm{pH}$ value of 6 was required for maximum dextranase activity (Figures 8 and 9). The produced enzyme was remarkably stable in the $\mathrm{pH}$ range of
5.0-8.0 (Figure 9). Therefore, the produced dextranase was highly thermal-stable and $\mathrm{pH}$-stable. However, for dextranase from Penicillium aculeatum, the optimum $\mathrm{pH}$ and temperature were found to be 4.5 and $45^{\circ} \mathrm{C}$, respectively [21]. The highest dextranase activity of Penicillium cyclopium was reported at $55^{\circ} \mathrm{C}$ and $5.0 \mathrm{pH}$ [46]. Interestingly, Chaetomium globosum dextranase could withstand a high temperature of $60^{\circ} \mathrm{C}$ and a low $\mathrm{pH}$ of 5.5 [31].

3.8.2. Effects of Several Factors and Compounds on Dextranase Activity. The effect of several compounds on dextranase activity was investigated considering the control (the reaction without the addition of such compounds) $100 \%$ activity (Table 2). The enzyme activity was increased in the presence of FeSO $4(1 \mathrm{mM}), \mathrm{MgSO}_{4}(10 \mathrm{mM})$, and $\left(\mathrm{NH}_{4}\right)_{2} \mathrm{SO}_{4}$ $(10 \mathrm{mM})$ by $17.7 \%, 12.6 \%$, and $18.8 \%$, respectively. Contrarily, $\mathrm{NaCl}(1 \mathrm{mM})$ addition was followed by decreased 


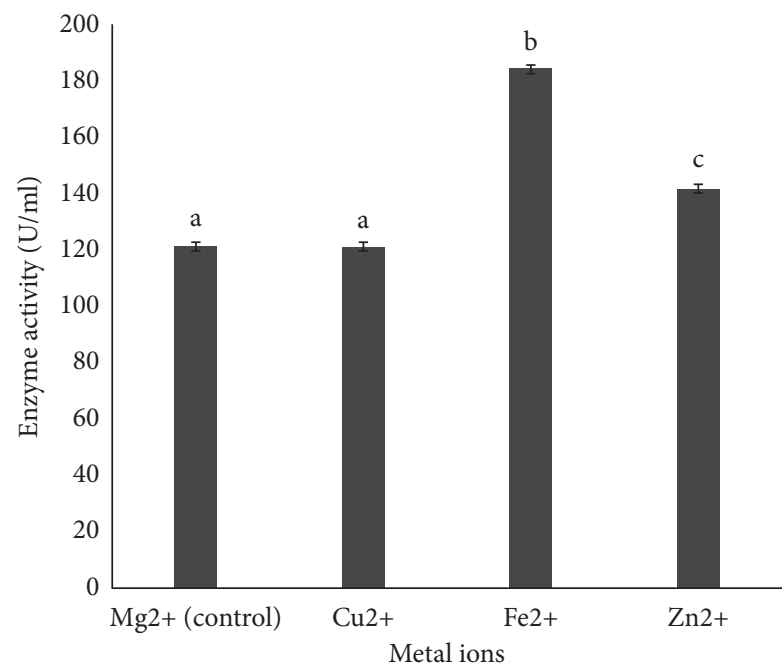

Figure 6: Effect of metal ions on dextranase production from Talaromyces sp. at the second day of fermentation. Symbols (mean \pm SE, $n=6$ ) having similar letters are not significantly different from each other (Bonferroni, $P<0.0125)$.

TABLE 1: Parameters related to purified dextranase from EGY strain.

\begin{tabular}{|c|c|c|c|c|c|}
\hline & Total activity (U) & Total protein $(\mathrm{mg})$ & $\begin{array}{l}\text { Specific activity } \\
(\mathrm{U} / \mathrm{mg})\end{array}$ & Fold of purification & Yield (\%) \\
\hline Crude dextranase & 8647 & 70 & 124 & 1 & 100 \\
\hline$\left(\mathrm{NH}_{4}\right)_{2} \mathrm{SO}_{4}$ precipitation (70\% saturation) & 1020 & 2.7 & 385 & 3 & 12 \\
\hline Sephadex G-100 & 480 & 0.1 & 3429 & 28 & 6 \\
\hline
\end{tabular}

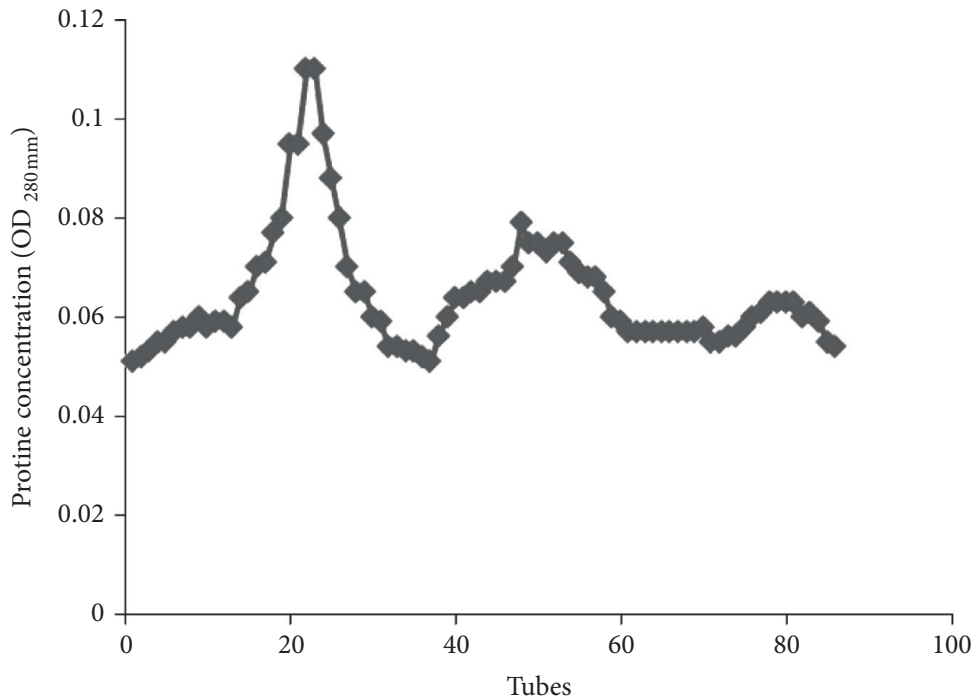

(a)

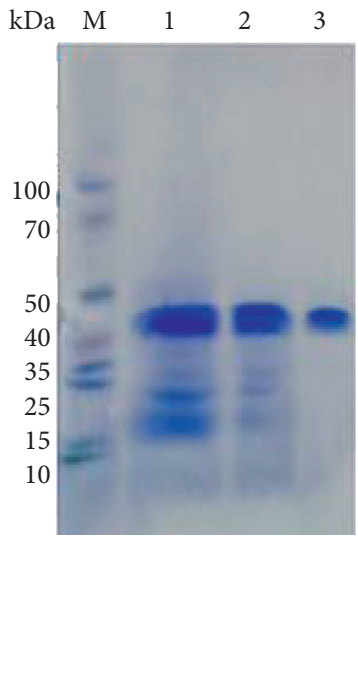

(b)

Figure 7: Purification of dextranase by Sephadex G-100 chromatography. (a) The protein concentrations of different tube fractions eluted from the Sephadex G-100 column. (b) Analysis of purified dextranase (tube fractions 19-22) by 12\% SDS-PAGE. Lane M: protein molecular mass marker (Thermo Scientific Spectra Multicolor Broad Range Protein Ladder); Lane 1: crude dextranase produced after optimization of production conditions; Lane 2: partially purified dextranase obtained by precipitation with $70 \%$ ammonium sulfate saturated solution; Lane 3: purified dextranase obtained by collecting of fraction tubes (19-22) after gel filtration chromatography. 


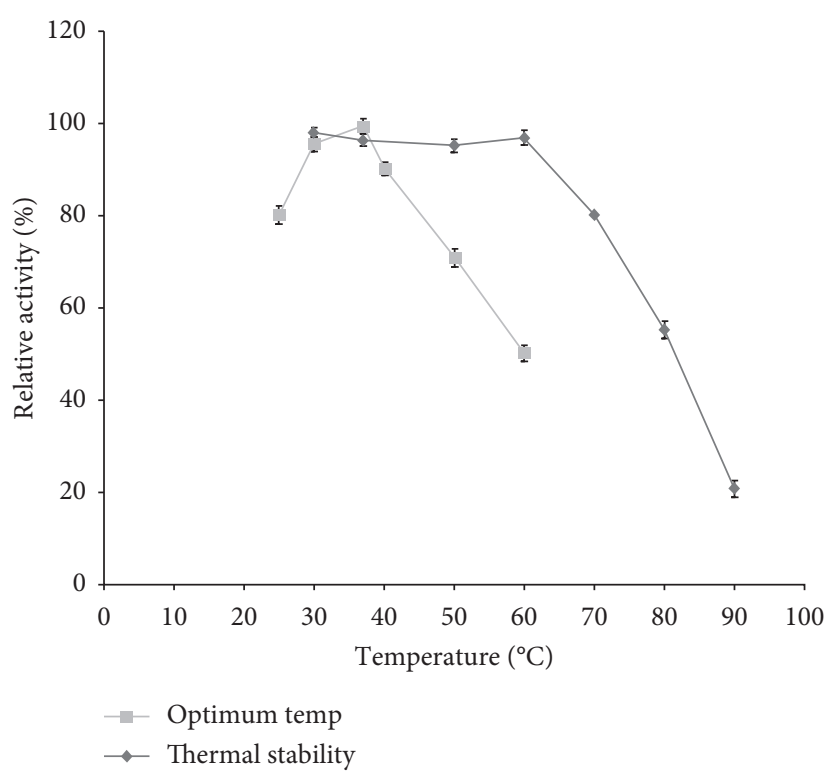

FIGURE 8: Effect of temperature on the activity and stability of dextranase from Talaromyces sp. Optimum temperature: activity was assayed by the standard method at different temperature values. Thermal stability: activity was assayed by the standard method after incubating the purified dextranase enzyme at different temperatures for $1 \mathrm{~h}$ without substrate addition. Error bars represent standard errors.

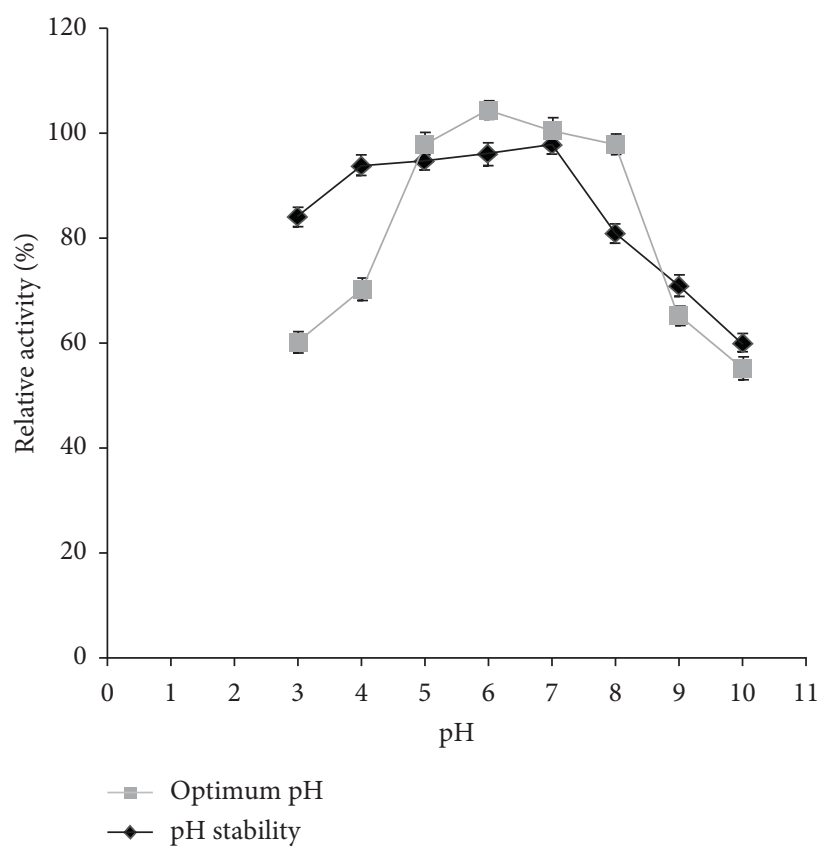

FIGURE 9: Effect of $\mathrm{pH}$ on the activity and stability of dextranase from Talaromyces sp. optimum $\mathrm{pH}$ : activity was assayed by the standard method at various $\mathrm{pH}$ values. $\mathrm{pH}$ stability: activity was assayed by the standard method after incubating the purified dextranase enzyme at different $\mathrm{pH}$ values for $1 \mathrm{~h}$ at $37^{\circ} \mathrm{C}$ without substrate addition. Error bars represent standard errors.

enzyme activity by $5.6 \%$. However, $\mathrm{Na}^{+}$and $\mathrm{Fe}^{2+}$ improved the enzymatic activity of Penicillium cyclopium [46]. In contrast, some results indicated that $\mathrm{FeCl}_{2}(1 \mathrm{mM})$ strongly inhibited the dextranase activity of Penicillium aculeatum and Chaetomium globosum [21, 31]. In the current study, the addition of EDTA $(10 \mathrm{mM})$ and SDS (5 $\mathrm{mM})$ was followed by reducing the enzyme activity to $9 \%$ and $12.6 \%$, respectively. Similar observations were detected for the enzyme activities of Chaetomium globosum and Talaromyces pinophilus that were slightly decreased by EDTA $(10 \mathrm{mM})$ by $8 \%$ and $17 \%$, 
TABLE 2: Effects of some metal ions and selected compounds on the activity of Talaromyces sp. dextranase enzyme.

\begin{tabular}{lccc}
\hline Compound & & Relative activity $\%$ & \\
& $1 \mathrm{mM}$ & $5 \mathrm{mM}$ & $10 \mathrm{mM}$ \\
\hline $\mathrm{MgSO}_{4}$ & 104 & 113 & 99 \\
$\left(\mathrm{NH}_{4}\right)_{2} \mathrm{SO}_{4}$ & 111 & 119 & 110 \\
$\mathrm{FeSO} 4$ & 118 & 95 & 94 \\
$\mathrm{NaCl}$ & 94 & 101 & 95 \\
$\mathrm{SDS}$ & 101 & 101 & 89 \\
$\mathrm{EDTA}$ & 92 & 100 & 91 \\
Control & 100 & 100 \\
\hline
\end{tabular}

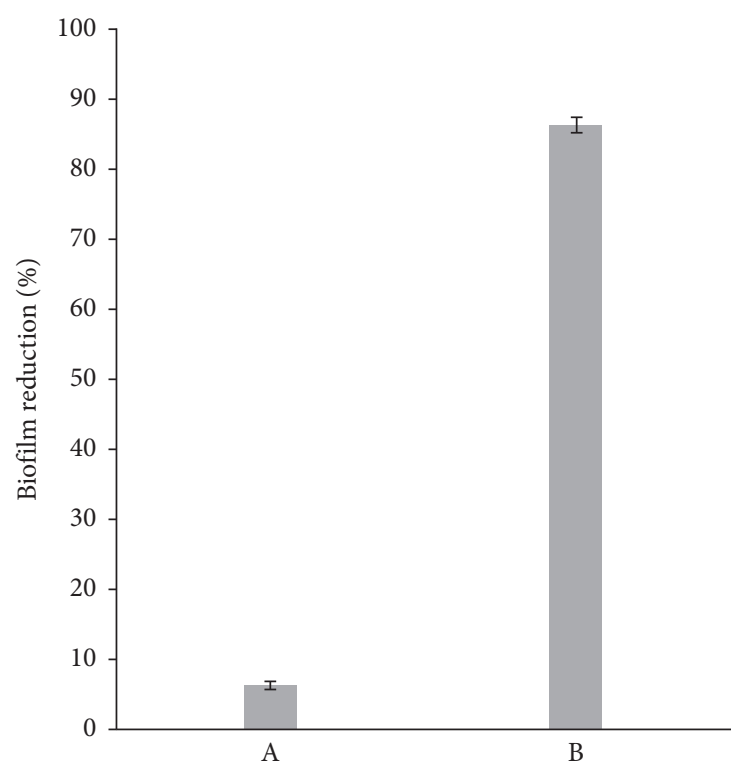

FIgUre 10: The effect of purified dextranase enzyme on biofilm formation of P. aeruginosa standard strain PAO1. (A) The dextranaseinhibitory effect on biofilm formation during bacterial cultivation. (B) The dextranase-reducing effect on $24 \mathrm{~h}$ old-established biofilm.

respectively [31, 45]. In contrast, Talaromyces pinophilus dextranase activity could be increased by $9 \%$ in SDS ( $5 \mathrm{mM})$ presence [45].

3.9. Effect of Dextranase Enzyme on Biofilm Formation of $P$. Aeruginosa Standard Strain PAO1. The effect of enzyme addition on old-established biofilm was previously documented [47]. In our study, the use of 5 units of the enzyme had $86 \%$ reducing activity on $24 \mathrm{~h}$ old-established biofilm of $P$. aeruginosa strain PAO1, adhering to the wall of the microtiter plate (Figure 10). Moreover, the biofilm formation was reduced by $6 \%$ when $P$. aeruginosa is cocultured with dextranase from Talaromyces sp. (Figure 10). A similar consequence was observed in the case of Catenovulum sp. as 40 units of catenovulum dextranase impeded biofilm formation in BHI media and reduced the cell population of $S$. mutans adhering to the glass coverslips [38].

\section{Conclusion}

In summary, one fungal strain identified as Talaromyces sp. could produce a thermal-stable enzyme expressing high enzyme activity (approximately $120 \mathrm{U} / \mathrm{ml}$ ). Studying the factors affecting the enzyme production resulted in the conclusion that the best carbon source was dextran T2000 and that the optimum $\mathrm{pH}$ was 7.4. Likewise, the maximum enzyme yield was detected on the $2^{\text {nd }}$ day of incubation. Some variation in production conditions could be traced; the peptone used as a nitrogen source increased the enzyme production. $\mathrm{Fe}^{2+}$ and $\mathrm{Zn}^{2+}$ addition resulted in a significant increase in enzyme activity while $\mathrm{Cu}^{2+}$ addition had no significant difference in such activity. The crude enzyme extract was partially purified (3-fold) by precipitation with ammonium sulfate (70\% saturation) and then further purified (28-fold) by gel filtration chromatography. The purified dextranase was $45 \mathrm{kDa}$ with an optimum temperature of $37^{\circ} \mathrm{C}$ and an optimum $\mathrm{pH}$ of 6.0. Dextranase activity increased in the presence of $\mathrm{MgSO}_{4}, \mathrm{FeSO}_{4}$, and $\mathrm{NH}_{4} \mathrm{SO}_{4}$. In contrast, SDS and EDTA inactivated the enzyme. Furthermore, the purified dextranase reduced the $24 \mathrm{~h}$ old-established biofilm of $P$. aeruginosa standard strain PAO1 by $86 \%$ and inhibited the formation of biofilm to a lower extent ( $6 \%$ reduction) when cocultured with such bacterium. Finally, because of the high heat-stability and $\mathrm{pH}$ stability of the Talaromyces dextranase, endophytic fungi could be considered promising sources of 
dextranase enzyme having different applications in the industries.

\section{Data Availability}

All datasets generated or analyzed during this study are available upon reasonable request from the corresponding author.

\section{Disclosure}

This work was performed at the Microbiology Department, Faculty of Pharmacy, Mansoura University, Egypt.

\section{Conflicts of Interest}

The authors declare that they have no conflicts of interest.

\section{Acknowledgments}

The authors would like to thank Professor Dr. Ashraf Taha Khalil, Professor of Pharmacognosy, Faculty of Pharmacy, Mansoura University, for providing plant samples and his help in plant work. The authors would like to thank Mr. Mohamed Eladawy, Demonstrator in the Department of Microbiology and Immunology, Faculty of Pharmacy, Mansoura University, for helping in the biofilm chapter. Our special thanks are extended to Miss Rana Sherif, Former Researcher in Biochemistry Department, College of Arts and Science, Texas Tech University, for helping with English usage.

\section{References}

[1] D.-T. Wu, H.-B. Zhang, L.-J. Huang, and X.-Q. Hu, "Purification and characterization of extracellular dextranase from a novel producer, Hypocrea lixii F1002, and its use in oligodextran production," Process Biochemistry, vol. 46, no. 10, pp. 1942-1950, 2011.

[2] R. L. Sidebotham, "Dextrans," Advances in Carbohydrate Chemistry and Biochemistry, vol. 30, pp. 371-444, 1974.

[3] J. M. Lee and P. F. Fox, "Purification and characterization of Paecilomyces lilacinus dextranase," Enzyme and Microbial Technology, vol. 7, no. 11, pp. 573-577, 1985.

[4] E. Khalikova, P. Susi, and T. Korpela, "Microbial dextranhydrolyzing enzymes: fundamentals and applications," $M i$ crobiology and Molecular Biology Reviews, vol. 69, no. 2, pp. 306-325, 2005.

[5] G. A. Molodova, T. I. Danilova, V. I. Maximov, and N. P. Kozhevnikova, "Methods of purifying dextranase from Penicillium funiculosum," Prikl Microbiology, vol. 16, pp. 907-914, 1980.

[6] B. Ingelman, H. Malmgren, J. Fakstorp, S. Lång, E. Turunen, and A. Tuhkanen, "Enzymatic breakdown of dextran," Acta Chemica Scandinavica, vol. 2, pp. 803-812, 1948.

[7] D. Kim and D. F. Day, "A new process for the production of clinical dextran by mixed-culture fermentation of Lipomyces starkeyi and Leuconostoc mesenteroides," Enzyme and Microbial Technology, vol. 16, no. 10, pp. 844-848, 1994.

[8] R. Mehvar, "Dextrans for targeted and sustained delivery of therapeutic and imaging agents," Journal of Controlled Release, vol. 69, no. 1, pp. 1-25, 2000.
[9] S. N. Thitaram, C.-H. Chung, D. F. Day, A. Hinton, J. S. Bailey, and G. R. Siragusa, "Isomaltooligosaccharide increases cecal Bifidobacterium population in young broiler chickens," Poultry Science, vol. 84, no. 7, pp. 998-1003, 2005.

[10] S. Bhatia, G. Bhakri, M. Arora, S. K. Uppal, and S. K. Batta, "Dextranase production from Paecilomyces lilacinus and its application for dextran removal from sugarcane juice," Sugar Tech, vol. 12, no. 2, pp. 133-138, 2010.

[11] R. Fulcher and P. Inkerman, "Preliminary studies on the enzymic "removal" of dextran from deteriorated cane juice," in Proceedings of the Australian Society of Sugar Cane Technology, vol. 41, pp. 179-186, Bundaberg, Australia, 1974.

[12] J. Cuddihy, F. Mendez, J. Rauh, and C. Bernhard, Dextranase in Sugar Production: Factory Experience, Midland Research Laboratories Inc., Lenexa, KS, USA, 1999.

[13] P. Jaiswal and S. Kumar, "Impact of media on isolation of dextranase producing fungal strains," Journal of Scientific Research, vol. 55, pp. 71-76, 2011.

[14] W. N. Arnold, T. B. P. Nguyen, and L. C. Mann, "Purification and characterization of a dextranase from Sporothrix schenckii," Archives of Microbiology, vol. 170, no. 2, pp. 91-98, 1998.

[15] E. Khalikova, P. Susi, N. Usanov, and T. Korpela, "Purification and properties of extracellular dextranase from a Bacillus sp," Journal of Chromatography B, vol. 796, no. 2, pp. 315-326, 2003.

[16] D. K. Das and S. K. Dutta, "Purification, biochemical characterization and mode of action of an extracellular endodextranase from the culture filtrate of Penicillium lilacinum," The International Journal of Biochemistry \& Cell Biology, vol. 28, no. 1, pp. 107-113, 1996.

[17] M. A. Abdel-Naby, A.-M. S. Ismail, A. M. Abdel-Fattah, and A. F. Abdel-Fattah, "Preparation and some properties of immobilized Penicillium funiculosum 258 dextranase," Process Biochemistry, vol. 34, no. 4, pp. 391-398, 1999.

[18] D. Kim, J. F. Robyt, S.-Y. Lee, J.-H. Lee, and Y.-M. Kim, "Dextran molecular size and degree of branching as a function of sucrose concentration, $\mathrm{pH}$, and temperature of reaction of Leuconostoc mesenteroides B-512FMCM dextransucrase," Carbohydrate Research, vol. 338, no. 11, pp. 1183-1189, 2003.

[19] S. Kusari, S. Singh, and C. Jayabaskaran, "Biotechnological potential of plant-associated endophytic fungi: hope versus hype," Trends in Biotechnology, vol. 32, no. 6, pp. 297-303, 2014.

[20] Y. Mishra, A. Singh, A. Batra, and M. M. Sharma, "Understanding the biodiversity and biological applications of endophytic fungi: a review," Journal of Microbial \& Biochemical Technology, vol. S8, no. 4, 2014.

[21] K. F. Mahmoud, A. Y. Gibriel, A. A. Amin, M. N. Nessrien, N. M. Yassien, and H. A. El Banna, "Microbial production and characterization of dextranase," International Journal of Current Microbiology and Applied Sciences, vol. 3, no. 9, pp. 1095-1113, 2014.

[22] A. H. Ali, U. Radwan, S. El-Zayat, and M. A. El-Sayed, "Desert plant-fungal endophytic association: the beneficial aspects to their hosts," Biological Forum-An International Journal, vol. 10, pp. 138-145, 2018.

[23] H. M. Farouk, E. Z. Attia, and M. M. H. El-Katatny, "Hydrolytic enzyme production of endophytic fungi isolated from soybean (glycine max)," Journal of Modern Research, $p$, vol. 2, no. 1, pp. 1-7, 2020.

[24] B. Jensen, J. Olsen, and K. Allermann, "Effect of media composition on the production of extracellular amylase from 
the thermophilic fungus Thermomyces lanuginosus," Biotechnology Letters, vol. 9, no. 5, pp. 313-316, 1987.

[25] T. Subasioglu and E. Cansunar, "Optimization of culture conditions and environmental factors of dextranase enzyme produced by Paecilomyces lilacinus," Hacettepe Journal of Biology and Chemistry, vol. 38, pp. 159-164, 2010.

[26] Y. Shao and A. H.-M. Lin, "Improvement in the quantification of reducing sugars by miniaturizing the Somogyi-Nelson assay using a microtiter plate," Food Chemistry, vol. 240, pp. 898-903, 2018.

[27] N. Nelson, "A photometric adaptation of the Somogyi method for the determination of glucose," Journal of Biological Chemistry, vol. 153, pp. 375-380, 1944.

[28] M. Somogyi, "Notes on sugar determination," Journal of Biological Chemistry, vol. 195, pp. 19-23, 1952.

[29] A. S. Al-doori, A. H. Aboud, and Z. T. Sedrah, "Optimization and characterization of dextransucrase production by local leuconostoc mesenteroides," International Journal of Scientific Engineering and Applied Science, vol. 1, no. 6, 2015.

[30] M. M. Bradford, "A rapid and sensitive method for the quantitation of microgram quantities of protein utilizing the principle of protein-dye binding," Analytical Biochemistry, vol. 72, no. 1-2, pp. 248-254, 1976.

[31] L. Yang, N. Zhou, and Y. Tian, "Purification, characterization, and biocatalytic potential of a novel dextranase from Chaetomium globosum," Biotechnology Letters, vol. 40, no. 9-10, pp. 1407-1418, 2018.

[32] U. K. Laemmli, "Cleavage of structural proteins during the assembly of the head of bacteriophage T4," Nature, vol. 227, no. 5259, pp. 680-685, 1970.

[33] M. Hukic, D. Seljmo, A. Ramovic et al., "The effect of lysozyme on reducing biofilms by Staphylococcus aureus, Pseudomonas aeruginosa, and Gardnerella vaginalis: an in vitro examination," Microbial Drug Resistance, vol. 24, no. 4, pp. 353-358, 2018.

[34] Y. M. Díaz, G. V. Laverde, L. R. Gamba, H. M. Wandurraga, and C. Arévalo-Ferro, "Biofilm inhibition activity of compounds isolated from two Eunicea species collected at the Caribbean Sea," Revista Brasileira de Farmacognosiap, vol. 25, no. 6, pp. 605-611, 2015.

[35] G. O'toole, H. B. Kaplan, and R. Kolter, "Biofilm formation as microbial development," Annual Review of Microbiology, vol. 54, pp. 49-79, 2000.

[36] J. L. D. C. Lima, L. R. Alves, J. N. P. D. Paz, M. A. Rabelo, M. A. V. Maciel, and M. M. C. de Morais, "Analysis of biofilm production by clinical isolates of Pseudomonas aeruginosa from patients with ventilator-associated pneumonia," Revista Brasileira de Terapia Intensiva, vol. 29, no. 3, pp. 310-316, 2017.

[37] S. Stepanovic, I. Cirkovic, L. Ranin, and M. Svabic-Vlahovic, "Biofilm formation by Salmonella spp. and Listeria monocytogenes on plastic surface," Letters in Applied Microbiology, vol. 38, no. 5, pp. 428-432, 2004.

[38] R. Cai, M. Lu, Y. Fang et al., "Screening, production, and characterization of dextranase from Catenovulum sp," Annals of Microbiology, vol. 64, no. 1, pp. 147-155, 2014.

[39] E. Shimizu, T. Unno, M. Ohba, and G. Okada, "Purification and characterization of an isomaltotriose-producing endodextranase from a Fusariumsp," Bioscience, Biotechnology, and Biochemistry, vol. 62, no. 1, pp. 117-122, 1998.

[40] J. Fukumoto, H. Tsuji, and D. Tsuru, "Studies on mold dextranases: 1. Penicillium luteum dextranase: its production and some enzymatic properties," The Journal of Biochemistry, vol. 69, no. 6, pp. 1113-1121, 1971.
[41] R. R. Zohra, A. Aman, R. R. Zohra, A. Ansari, M. Ghani, and S. A. U. Qader, "Dextranase: hyper production of dextran degrading enzyme from newly isolated strain of Bacillus licheniformis," Carbohydrate Polymers, vol. 92, no. 2, pp. 2149-2153, 2013.

[42] A. Mahmoud and W. Helmy, "Application of cold-active dextranase in dextran degradation and isomaltotriose synthesis by micro-reaction technology," Australian Journal of Basic and Applied Sciences, vol. 3, no. 4, pp. 3808-3817, 2009.

[43] S. M. Wakil, O. J. Ibikunle, and H. A. Akinyele, "Production and characterization of dextranase by Penicillium brevicompactum isolated from garden soil," Journal of Advances in Microbiology, vol. 13, no. 4, pp. 1-12, 2018.

[44] H. G. El-Masry, "Optimization of dextranase synthesis by a locally isolated Fusarium moniliforme (12)," Zentralblatt für Mikrobiologie, vol. 146, no. 3, pp. 185-192, 1991.

[45] Y.-Q. Zhang, R.-H. Li, H.-B. Zhang, M. Wu, and X.-Q. Hu, "Purification, characterization, and application of a thermostable dextranase from Talaromyces pinophilus," Journal of Industrial Microbiology \& Biotechnology, vol. 44, no. 2, pp. 317-327, 2017.

[46] R. Huang, L. Zhong, F. Xie et al., "Purification, characterization and degradation performance of a novel dextranase from Penicillium cyclopium CICC-4022," International Journal of Molecular Sciences, vol. 20, no. 6, p. 1360, 2019.

[47] M. Eladawy, M. El-Mowafy, M. M. A. El-Sokkary, and R. Barwa, "Effects of lysozyme, proteinase $\mathrm{K}$, and cephalosporins on biofilm formation by clinical isolates of Pseudomonas aeruginosa," Interdisciplinary Perspectives on Infectious Diseases, vol. 2020, Article ID 6156720, 9 pages, 2020. 